\title{
Head and Neck Cellulitis of Dental Origin and HIV Infection: 24 Cases
}

\author{
Amady Coulibaly ${ }^{1,2 *}$, Abdoulaye Kassambara1,2, Youssouf Sidibé2,3, Diomanténé Camara1, \\ Abdramane S. Maïga1, Kadia Keita1, Alphousseiny Touré1,2, Boubacar Ba ${ }^{1,2}$, Hamady Traoréé,2, \\ Daouda K. Minta ${ }^{2,4}$
}

\author{
${ }^{1}$ Department of Stomatology and Maxillofacial Surgery, CHU-CNOS, Bamako, Mali \\ ${ }^{2}$ Faculty of Medicine and Odontostomatology, Bamako, Mali \\ ${ }^{3}$ Departement of Otorhinolaryngology, CHU Mère-Enfant "le Luxembourg", Bamako, Mali \\ ${ }^{4}$ Department of Infectious Diseases, CHU-Point G, Bamako, Mali \\ Email: *coulibalyamady@yahoo.fr
}

How to cite this paper: Coulibaly, A., Kassambara, A., Sidibé, Y., Camara, D., Maïga, A.S., Keita, K., Touré, A., Ba, B., Traoré, H. and Minta, D.K. (2022) Head and Neck Cellulitis of Dental Origin and HIV Infection: 24 Cases. International Journal of Otolaryngology and Head \& Neck Surgery, 11, 1824.

https://doi.org/10.4236/ijohns.2022.111003

Received: October 15, 2021

Accepted: December 14, 2021

Published: January 7, 2022

Copyright $\odot 2022$ by author(s) and Scientific Research Publishing Inc. This work is licensed under the Creative Commons Attribution International License (CC BY 4.0).

http://creativecommons.org/licenses/by/4.0/ (c) (i) Open Access

\begin{abstract}
Cervico-facial cellulitis is a serious poly-microbial infection of the deep fascial spaces of the face and neck which may be life-threatening. The existence of an underlying ground that causes immune failure may promote or complicate this infection. The aim of this work was to describe the socio-demographic and clinical aspects of dental cervicofacial cellulitis associated with HIV in our context. It was a descriptive cross-sectional study that concerned all cases of cervico-facial cellulitis with positive HIV serology encountered at the CHUCNOS of Bamako from May 2017 to January 2018. Twenty-four cases were collected. Cellulite with positive HIV accounted for $1.14 \%$ of consultations in the service. Females accounted for $67.66 \%$ of cases with a sex ratio of 0.5 . The average age was 33.58 years old. Housewives accounted for $33.33 \%$ of cases. The bride and groom represented $83 \%$ of the cases. The triad (pain, swelling, and trismus) was the most common reason for consultation with $41.7 \%$ of cases. The tooth 37 was involved in $25 \%$ of the cases. In $87 \%$ of cases, patients were screened in the service. HIV-1 was found in $75.0 \%$ of cases. Complications such as peripheral facial palsy were found in three cases. The medico-surgical treatment was performed in 23 cases with a favorable evolution. The search for an underlying ground, in particular HIV infection, must be systematic in the face of diffuse cervicofacial cellulitis.
\end{abstract}

\section{Keywords}

Cellulitis, Cervico-Facial, Infection, HIV 


\section{Introduction}

Head and neck cellulitis are serious infections of the deep aponeurotic spaces of the face and neck that can be life-threatening [1]. The germs involved, usually harmless in healthy individuals, may find the opportunity to develop in bone and gum lesions induced by neglected dental caries, accidents in the development of dentition or periodontitis as well as tonsillitis [2]. They can be the consequence of an incomplete or inappropriate treatment or the consequence of an abusive and unjustified prescription of non-steroidal anti-inflammatory drugs (NSAIDs) and/or an underlying favorable ground responsible for an immunosuppression (diabetes, HIV) [3]. In Mali, according to the 2012-2013 Demographic and Health Survey, HIV prevalence is $1.1 \%$ [4]. In fact, nearly $60 \%$ of patients infected with HIV present with ENT or cervico-facial involvement during the disease [5].

The objective of this work was to describe the socio-demographic and clinical aspects of dental cervicofacial cellulitis associated with HIV in our context.

\section{Patients and Methods}

This was a descriptive cross-sectional study with retrospective collection, carried out in the department of stomatology and maxillofacial surgery of the CHUCNOS in Bamako. It took place from May 1, 2017 to January 31, 2018. It was included, all patients with head and neck cellulitis with positive HIV serology on the ELISA test and who accepted the proposed treatment. It was excluded from this study, all patients with head and neck cellulitis with positive HIV serology who had an incomplete medical file or who did not accept the proposed treatment. A total of 24 cases were included. Data entry and analysis were carried out using SPSS French version 25 software. Ethical considerations were taken into account.

\section{Results}

It was collected during the study period 24 cases. Cellulitis with positive HIV accounted for $1.14 \%$ consultations in the department and $2.85 \%$ of cellulite cases encountered over the same period. Females represented $67 \%$ of cases and the sex ratio was 2 . The 25 - 35 age group was the most represented with $45.8 \%$ of cases (Table 1). The mean age was 33.58 years with a standard deviation of 9.88 . The minimum age was 19 and the maximum was 61 . Most of the patients resided outside Bamako, i.e. $41.67 \%$ of cases. The married represented $83 \%$ of the cases. Housewives were the most affected with a rate of $33.33 \%$. Active smoking was found in $25 \%$ of cases. One case of type 2 diabetes and one case of pregnancy were observed in the series while drug addiction was observed in 6 cases. The consultation time was greater than 14 days in the majority of cases, i.e. $71 \%$. The traditional treatment recourse before the consultation was found in $50 \%$ of cases. The general condition was not altered in $91 \%$ of cases. The triad (pain + swelling + trismus) was found in $41.7 \%$ of patients. Oral condition was poor in $54 \%$ of 
cases. The traditional toothbrush stick was the most widely used means of hygiene with a rate of $58.33 \%$. The front door was exclusively dental and related to dental caries. The lower left second molar was the most common causal tooth in $25 \%$ of cases (Table 2). Peripheral facial paralysis was associated with the clinical picture in 3 cases either a rate or $12.5 \%$ of cases. Compression of the upper aerodigestive tract was encountered in one case, i.e. $4.2 \%$ of cases. HIV1 was found in $75 \%$ while the combination of HIV1 and 2 in $16.7 \%$ of cases (Table 3). Only $12.5 \%$ of HIV serologic cases were diagnosed and on antiretroviral therapy before admission to the ward. Pseudomonas aeroginosa and Staphylococcus aureus were found in one case each. Panoramic X-ray was the most performed examination with a rate of $50 \%$ (Table 4). Hospitalization affected $91.7 \%$ of cases with an average duration of 15 days. All patients received medical treatment with

Table 1. Distribution of patients according to age group.

\begin{tabular}{ccc}
\hline Age group & Frequency & Percent \\
\hline 25 ans & 5 & 20.8 \\
$25-35$ ans & 11 & 45.8 \\
$36-45$ ans & 5 & 20.8 \\
$46-55$ ans & 2 & 8.3 \\
$>55$ ans & 1 & 4.2 \\
Total & 24 & 100
\end{tabular}

Table 2. Distribution of patients according to the tooth concerned.

\begin{tabular}{ccc}
\hline Affected tooth & Frequency & Percent \\
\hline 16 & 2 & 8.3 \\
25 & 1 & 4.2 \\
36 & 6 & 25.0 \\
37 & 5 & 20.8 \\
38 & 2 & 8.3 \\
46 & 4 & 16.7 \\
47 & 4 & 16.7 \\
Total & 24 & 100 \\
\hline
\end{tabular}

Table 3. Distribution of patients according to the type of HIV.

\begin{tabular}{ccc}
\hline HIV type & Frequency & Percent \\
\hline HIV 1 & 18 & 75.0 \\
HIV 2 & 2 & 8.3 \\
HIV 1 + HIV 2 & 4 & 16.7 \\
Total & 24 & 100 \\
\hline
\end{tabular}


Table 4. Distribution of patients according to the radiological examination carried out.

\begin{tabular}{ccc}
\hline radiological examination & Frequency & Percent \\
\hline Radio panoramique & 12 & 50 \\
Radio pulmonaire & 4 & 16.7 \\
Echographie obstétricale & 1 & 4.17 \\
TDM cervico-faciale & 1 & 4.17
\end{tabular}

Table 5. Distribution of patients according to evolution.

\begin{tabular}{ccc}
\hline Evolution & Frequency & Percent \\
\hline Guérison & 23 & 95.83 \\
Décès & 1 & 4.17 \\
Total & 24 & 100 \\
\hline
\end{tabular}

antibiotics, analgesics and local care with mouthwashes. The incision-drainage was performed in $87.5 \%$ of patients under local anesthesia. The extraction of the causal tooth was performed in $85 \%$ of cases. The majority of cases, i.e. $87.5 \%$, which were detected in the service were then referred to the HIV and AIDS care units in Bamako. The outcome was favorable in $95.3 \%$ of cases after a onemonth follow-up. There was one case of hospital death (Table 5).

\section{Discussion}

Head and neck cellulitis of dental origin is still relevant in our practice. The prevalence of this pathology varies from country to country and within the same country depending on the care services [6] [7]. Although this frequency is relatively low in our study, it is far from reflecting the reality. The management of cellulitis is carried out both in ENT and head and neck surgery departments as well as in stomatology departments where higher rates are observed. Thus, BADOU KE et al. [6] report a hospital prevalence of cellulitis of 3.5\% with an annual incidence of 4.3 cases. Harding et al. in Côte d'Ivoire [7] reported a hospital prevalence of $22.5 \%$. Aswan et al. [8] published in 2012, an annual incidence of 57.66\% (173 cases over 3 years). Sereme et al. [9] in Burkina Faso found $1.02 \%$ cellulite over a 10-year period. In northern countries, cellulite has become increasingly rare [10] [11]. The pathology affects both sexes. Most of the authors [8] [9] [12] [13] [14] have observed a male predominance. A better immune response in women has been suggested by some authors to explain this predominance [15]. Women, more concerned about their appearance and their health, would consult early [6]. However, the female predominance observed in our context could be explained by the high prevalence of HIV in this segment of the Malian population.

Children as well as adults can be affected [6] [7] [15]. All age groups are represented in our study. The average age was 33.58 years. It appears fairly clas- 
sically in the literature that head and neck cellulitis is particularly common in the 20 to 40 year age group [15]. They affect people who are immunocompetent or not. On the other hand, immune deficiencies favor the appearance of gangrenous cellulitis, real necrotizing fasciitis with a formidable prognosis, fortunately rare. Although the search for HIV serology is not systematic in practice, it is not uncommon to find positive HIV serology as a pre-existing defect in patients with diffuse head and neck cellulitis. It is performed in the presence of an unusual clinical picture due to its severity and its resistance to treatment [15]. Badou Ke et al. [6] found 9.6\% of cases of HIV infection out of 73 cases of cervical and facial cellulitis. Roberto Manfredi et al. [16] reported 63 cases of cellulitis associated with HIV. These disease states lead to immune depression which promotes the spread of the infection and its aggravation [7] [8].

Taking NSAIDs, readily prescribed (or self-prescribed) for dental pain, is a predictor of the severity of dental cellulitis [17]. Many authors [6] [12] [17] have identified NSAIDs as factors that promote cellulitis. The mechanism of this aggravation is either related to a major decrease in pain masking the signs of progression, or to a role in favoring infection by decreased immunity. Likewise, the misuse of antibiotics, always in self-medication, causes an increase in the resistance and virulence of germs. This high rate of taking NSAIDs is mainly due to the fact that they are over-the-counter in our regions and cost less. They have a spectacular analgesic effect on odontalgia. A positive diagnosis of head and neck cellulitis should be made as soon as possible, in order to establish an effective therapeutic strategy. The clinical sign found in all of our files was that of an inflammatory swelling, which is also the most frequent reason for consultation in the literature [15]. Dental etiology is frequently encountered [6] [7] [17] [18]. Oral condition was poor in $54 \%$ of cases in our setting. The lower left second molar was the most common causal tooth in $25 \%$ of cases. Involvement of the lower molars has been frequently observed in the literature [6] [9] [12]. However, in France, Mateo [19] noted a predominance of pharyngeal involvement in $50 \%$ of cases followed by dental involvement in about $20 \%$ of cases.

The orthopantomogram was performed in $50 \%$ of our patients. The radiological assessment takes all its value in the diagnosis and monitoring of cervico-facial and especially cervico-mediastinal cellulitis. Head and neck computed tomography with sections of the mediastinum to confirm the diagnosis, specify the extension as well as the uni or bilaterality of the lesions, and look for associated infectious mediastinal involvement [15]. Treatment involves antibiotic therapy, surgical treatment, resuscitation if necessary, balancing of existing defects, and treatment of the origin of the infection. The management of cellulitis must be extremely rapid in the event of compression of the VADS or in the event of the development of gangrenous diffusion [17]. Broad-spectrum antibiotic therapy, initially active on all the germs potentially responsible for this infection, most often polymicrobial, prolonged and by parenteral route, should be instituted urgently, if possible after taking a bacteriological sample and blood 
cultures [6] [15]. This antibiotic therapy is probabilistic at first, as in our context targeting streptococci and strict commensal anaerobes.

The etiological treatment can be conservative or radical; it is usually done after the infection has cooled [15]. The majority of tooth extraction has been practiced in our context. Conservative treatment is endodontic treatment of the tooth responsible for the infection. Always take into account the general condition, the size of the tooth, the level of oral hygiene, and the principle of preservation when possible [20]. Balancing existing defects is essential in management. In our context, all patients after HIV screening were referred to the HIV and AIDS care units in Bamako. Diabetes is also the subject of specialized care.

\section{Conclusion}

Cervico-facial cellulitis is a medico-surgical emergency for which the management is multidisciplinary. The existence of an underlying ground responsible for a failure of the immune system in this case HIV can promote infection or complicate it. This underlying ground can even be discovered in the course of their taking charge. Under appropriate treatment with monitoring, they can evolve favorably.

\section{Conflicts of Interest}

The authors declare no conflicts of interest regarding the publication of this paper.

\section{References}

[1] Blancal, J.P., Kania, R., Sauvaget, E., et al. (2010) Management of Cervicofacial Cellulitis in Intensive Care. Réanimation, 19, 298. https://doi.org/10.1016/j.reaurg.2010.04.001

[2] Razafindrabe, J.A.B., Randriamanaatenasoa, V.H. andrianasolo, M.F., Radavarison, J.B., et al. (2007) Epidemiological and Clinical Aspects of Dental Cellulitis in Antananarivo. Journal of Medical Science, 7, 1108-1111. https://doi.org/10.3923/jms.2007.1108.1111

[3] Eter, E.G., Khazzaka, A., Mneimneh, W., et al. (2009) Doe Diclofenac Increase the Risk of Cervical Necrotizing Fasciitis in a Rat Model? International Journal of Experimental Pathology, 90, 58-65. https://doi.org/10.1111/j.1365-2613.2008.00594.x

[4] Mali Demographic and Health Survey 2012-2013. The Prevalence of HIV in Mali's EDSM-V from 2012-2013.

[5] Jaquet, Y. and Maire, R. (2002) Otoneurological Manifestations Linked to HIV Infection: Presentation of a Case of Facial Paralysis and Review of the Literature. Revue med de la suisse romande, 122, 269-271.

[6] Badou, K., Buraima, F., Yoda, M., Traore, K., Kouassi, Y., Tanon-Anoh, M. and Kouassi, B. (2014) Cervico-Facial Cellulitis at the Yopougon University Hospital Center (Abidjan-Cote D'ivoire). Journal of the African College of Odontostomatology and Maxillofacial Surgery, 21, 5-10.

[7] Harding, M.B., Aka, K.G., Ouattara, B., Konsem, T., Bandama, K.J., Aka, F., et al. (2001) Role of Nonsteroidal Anti-Inflammatory Drugs in Maxillofacial Cellulitis. African Journal of Surgery, 4, 4-7. 
[8] Assouan, C., Anzouan, K., Aka-Adouko, J.A., Millogo, M., N'Guessan, N., Diomande, A., et al. (2012) Management of Cellulite in Diabetics. Journal of the African College of Odontostomatology and Maxillofacial Surgery, 19, 16-19.

[9] Sereme, M., Ouedraogo, B., Gyebre, Y., Ouattara, M. and Ouoba, K. (2010) Head and Neck Cellulitis: About 26 Cases. La Revue Africaine d ORL et de Chirurgie cervico-faciale, 9, 23-28.

[10] Mohammedi, I., Ceruse, P. and Duperret, S. (1999) Cervical Necrotizing Fasciitis: 10 Years' Experience at a Single Institution. Intensive Care Medicine, 25, 829-834. https://doi.org/10.1007/s001340050959

[11] Tung-Yiu, W., Jehn-Shyun, H., Ching-Hung, C. and Huang-An, C. (2000) Cervical Necrotizing Fasciitis of Odontogenic Origin: A Report of 11 Cases. Journal of Oral and Maxillofacial Surgery, 58, 1347-1352. https://doi.org/10.1053/joms.2000.18259

[12] Benzarti, S., Mardassi, A., Ben Mhamed, R., Hachicha, A., Brahem, H., Akkari, K., et al. (2007) Head and Neck Cellulitis of Dental Origin: About 150 Cases. Tunisian ORL Journal, 19, 24-28.

[13] Djomou, F., Mindja, E.D., Ngo, I.A.R., Asmaou, D., Ndjolo, A. and Bengolo, G. (2010) Head and Neck Cellulitis in Adults in Yaoundé. La revue africaine d ORL et de chirurgie cervico-faciale, 9, 15-22.

[14] Keita, M., Doumbi, A.K., Diango, D., Diallo, M., Timbo, S.K. and Mohamed, A. (2008) Cervical Cellulitis in a Sub-Sahelian Hospital Environment. A Forgotten Pathology? Case of Mali. Médecine d'Afrique Noire, 55, 8-9.

[15] El Ayoubi, A., El Ayoubi, F., Mas, E., et al. (2009) Diffuse Cervicofacial Cellulitis of Dental Origin: About 60 Cases. Medecine Buccale Chirurgie Buccale, 15, 127-135. https://doi.org/10.1051/mbcb/2009011

[16] Manfredi, R., Calza, L. and Chiodo, F. (2002) Epidemiology and Microbiology of Cellulitis and Bacterial Soft Tissue Infection during HIV Disease: A 10-Year Survey. Journal of Cutaneous Pathology, 29, 168-172. https://doi.org/10.1034/j.1600-0560.2002.290307.x

[17] Bertolus, Ch. (2011) Cervico-Facial Cellulitis. Urgences, 594-599.

[18] Marcelle, E., Olivier, D. and Chanelle, L. (2020) Odontogenic Cervico-Facial Cellulitis at the University Hospital of Brazzaville: About 431 Cases. Journal Ouvert de Stomatologie, 10, 19-27. https://doi.org/10.4236/ojst.2020.102003

[19] Mateo, J., Petipas, F. and Payen, D. (2006) Severe Cervical Skin and Soft Tissue Infections and Necrotizing Fasciitis. Annales Françaises d Anesthésie et de Réanimation, 25, 975-977. https://doi.org/10.1016/j.annfar.2006.03.019

[20] Zilberstein, B., de Cleva, R., Testa, R.S., Sene, U., Eshkenazy, R. and Gama-Rodrigues, J.J. (2005) Cervical Necrotizing Fasciitis Due to Bacterial Tonsillitis. Clinics (Sao Paulo), 60, 177-182. https://doi.org/10.1590/S1807-59322005000200015 